\title{
Information Systems Academic Program Assessment: A Comparison Of Objective And Subjective Approaches
}

Charles H. Mawhinney, (E-mail: mawhinnc@mscd.edu), Metropolitan State College of Denver

\begin{abstract}
Developing program assessment instruments and methodologies is a common problem in higher education. This paper reports on a study that compared an objective instrument against a subjective instrument for measuring program learning objectives. The results indicate that at least four of the seven learning objectives apparently are being measured by the objective instrument.
\end{abstract}

\section{Introduction}

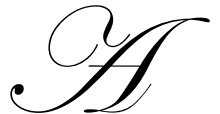

little over a decade ago, the State of Colorado mandated that all public institutions of higher learning establish a system for assessing the quality of their degree programs. In the Computer Information Systems Department at our institution we developed an assessment plan to meet that requirement. We first developed a set of learning objectives in the form of knowledge goals and skill goals. We then developed an objective test to assess the knowledge goals.

Over the past eight years in which this program has been in operation, the degree program requirements, the learning objectives, and the assessment test have all been modified somewhat to address the changing nature of the information systems profession. At present, there are seven knowledge goals. The objective portion of the assessment test currently consists of 135 multiple choice questions arranged into six topic groups. For the most part the questions came from examinations given in the core courses in the CIS degree. Graduating seniors in the CIS degree program are required to take the test. In recent years the test has been administered online through a password protected exam system.

Two years ago in an attempt to broaden our program assessment activities, we began to seek input from our alumni regarding how well they thought we were achieving our program objectives. We developed a subjective instrument in which we asked how well we were meeting each of our twelve learning objectives, with a three-point response scale: 1) Worse than expected, 2) About as expected, and 3) Better than expected. This set of questions was also incorporated into the assessment test which we have been giving to our graduating seniors.

This study focused on a comparison of the student responses for the two types of questions (objective versus subjective) for the Knowledge Goals. The following null hypothesis was tested:

$\mathbf{H}_{0}: \quad$ The two types of instrument do not measure the same attributes.

It will be tested against the following alternative hypothesis:

$\mathbf{H}_{\mathrm{A}}: \quad$ The two types of instrument do measure the same attributes.

Readers with comments or questions are encouraged to contact the author via email. 


\section{Methodology}

The Instrument

The subjective instrument for the Knowledge Goals is shown in the Appendix. The wording for these seven Knowledge Goals was taken directly from our approved Assessment Plan. The responses were assigned values after the fact of:

$1=$ Worse than expected, $2=$ About as expected, $3=$ Better than expected.

Four of these Knowledge Goals map directly into core courses that all our majors must take:

- $\quad$ Systems Analysis and Design

- $\quad$ Business Problem Solving: A Structured Programming Approach

- $\quad$ File Design and Database Management

- Telecommunications Systems

The objective instrument consisted of six sections of multiple choice questions, four sections of which were created to reflect the four areas described above. The questions were taken from examinations used in those four courses. Each set consisted of 20 or 25 questions. ${ }^{1}$

The assessment of the other three Knowledge Goals is somewhat problematic since we have no CIS core courses which directly address them. Goals \#1 and \#2 are addressed somewhat in our Business Core course, Computer Applications for Business, but the primary emphasis in that course in recent years has been on developing competence in handson computer skills. For a two-year period we did have a core course requirement that would address Goal \#4, but it was in the form of a constrained elective where a student had to take one of two possible courses (one was PC architecture and the other was PC operating systems), but no corresponding section was ever put on the Assessment Test. This goal is also addressed somewhat in the Computer Applications for Business course.

The other two sections of the Assessment Test are made up of a section of questions from the Computer Applications for Business course and a section of questions on computer literacy which is a subset of a screening test that we use for students entering the Computer Applications for Business course. In our annual assessment report we combine the results of these two sections and use that score for assessing Goals \#1, \#2, and \#4. In the assessment report and in this analysis, all scores were converted to percentages.

\section{The Sample Groups}

Graduating seniors in our CIS degree program are informed by email that they are required to take the test. Data from spring 2000, spring 2001, and fall 2001 were available for this analysis. Usable results were received from a total of 165 students.

\section{Results}

Scale Analysis

The data were analyzed using the SPSS/PC for Windows statistical package. Each of the two instruments was first analyzed using Correlation Analysis and then Factor Analysis to determine whether the items were independent of each other or resulted in a clustering (See Anderson, et al, 1994, Norusis, 1993, Tabachnick \& Fidell, 1983).

\footnotetext{
${ }^{1}$ The first version of the Assessment Test had 25 questions in each section. After the second year, new sections were added to the test, and the original sections were analyzed using item-total correlation analysis to reduce the number of questions to the 20 that were most statistically reliable.
} 
The correlation analysis of the seven subjective items is shown in Table 1 . Of the 21 pair-wise correlation values, all but four were statistically significant at $\mathrm{p} \leq 0.05$. All four of the non-significant correlations were associated with the item on Telecommunications. That item showed a significant correlation with item \#4 (Systems Architecture) and Item \#5 (Programming).

Table 1. Cross Correlations for Subjective Questions

\begin{tabular}{|c|c|c|c|c|c|c|c|c|c|c|c|c|c|c|c|c|}
\hline \multirow{3}{*}{\begin{tabular}{|l|} 
Item \\
Q01 \\
\end{tabular}} & \multirow{3}{*}{\begin{tabular}{|l} 
Mean \\
2.12
\end{tabular}} & \multirow{3}{*}{\begin{tabular}{|l|} 
Std Dev \\
0.45 \\
\end{tabular}} & \multicolumn{14}{|c|}{ Pierson Correlations } \\
\hline & & & \multicolumn{2}{|c|}{ Q01 } & \multicolumn{2}{|c|}{ Q02 } & \multicolumn{2}{|c|}{ Q03 } & \multicolumn{2}{|c|}{ Q04 } & \multicolumn{2}{|c|}{ Q05 } & \multicolumn{2}{|c|}{ Q06 } & \multicolumn{2}{|c|}{ Q07 } \\
\hline & & & 1.000 & & 0.437 & $* * *$ & 0.480 & $* * *$ & 0.394 & $* * *$ & 0.374 & $* * *$ & 0.400 & $* * *$ & 0.123 & \\
\hline Q02 & 2.01 & 0.45 & 0.437 & $* * *$ & 1.000 & & 0.307 & $* * *$ & 0.219 & ** & 0.222 & $* *$ & 0.242 & $* *$ & 0.104 & \\
\hline Q03 & 2.19 & 0.59 & 0.480 & $* * *$ & 0.307 & *** & 1.000 & & 0.428 & $* * *$ & 0.303 & $* * *$ & 0.294 & $* * *$ & 0.086 & \\
\hline Q04 & 1.95 & 0.61 & 0.394 & $* * *$ & 0.219 & $* *$ & 0.428 & $* * *$ & 1.000 & & 0.313 & $* * *$ & 0.155 & $*$ & 0.220 & *** \\
\hline Q05 & 2.16 & 0.64 & 0.374 & $* * *$ & 0.222 & $* *$ & 0.303 & $* * *$ & 0.313 & $* * *$ & 1.000 & & 0.289 & $* * *$ & 0.161 & $*$ \\
\hline Q06 & 2.16 & 0.66 & 0.400 & $* * *$ & 0.242 & $* *$ & 0.294 & $* * *$ & 0.155 & $*$ & 0.289 & *** & 1.000 & & -0.099 & \\
\hline Q07 & 2.28 & 0.69 & 0.123 & & 0.104 & & 0.086 & & 0.220 & $* *$ & 0.161 & $*$ & -0.099 & & 1.000 & \\
\hline $\begin{array}{ll}* * * & \mathrm{C} \\
* * & \mathrm{C} \\
* & \mathrm{C} \\
\end{array}$ & $\begin{array}{l}\text { tion is } \\
\text { tion is } \\
\text { ation is }\end{array}$ & $\begin{array}{l}\text { gnificant } \\
\text { ignificant } \\
\text { ignificant }\end{array}$ & $\begin{array}{l}\text { the } 0 \text {. } \\
\text { the } 0 \text {. } \\
\text { at the } 0 \text {. }\end{array}$ & $\begin{array}{l}0 \mathrm{lev} \\
0 \mathrm{lev}\end{array}$ & $\begin{array}{l}\text { el }(2-t a \\
\text { el }(2-t a \\
\text { el }(2-t a\end{array}$ & & & & & & & & & & & \\
\hline
\end{tabular}

Table 2. Factor Analysis of Subjective Questions

\begin{tabular}{|l|l|c|c|}
\hline Item & \multicolumn{1}{|c|}{ Description } & Factor 1 & Factor 2 \\
\hline Q01 & MIS & 0.798 & \\
\hline Q03 & Systems Analysis \& Design & 0.697 & \\
\hline Q06 & Database & 0.689 & \\
\hline Q02 & MIS Environment & 0.627 & 0.503 \\
\hline Q05 & Programming & 0.570 & 0.862 \\
\hline Q04 & Computer Architecture & 0.527 & \\
\hline Q07 & Telecommunications & & \\
\hline
\end{tabular}

When so many items are correlated with each other, it is appropriate to use Factor Analysis to investigate subgroupings. The responses to the subjective items were factor analyzed using the Principle Components method with Varimax Rotation. The results of this analysis are shown in Table 2. It resulted in two distinct factors, although one item (Computer Architecture) loaded almost equally on both factors. Item \#7 (Telecommunications) again showed its apparent uniqueness by being almost the only item on the second factor. It should also be noted that this item had the highest average response value and the other item on that factor (Computer Architecture) had the lowest average response value (see Table 1).

The correlation analysis of the six Assessment Instrument Components and the combined Computer Literacy/MIS component is shown in Table 3. All 21 pair-wise correlation values were statistically significant at $\mathrm{p} \leq 0.001 .^{2}$ The six components were factor analyzed using the same procedure described above. As shown in Table 4, this analysis yielded only one factor with all six components loading on it. These analyses suggest that the six components of the Assessment Instrument may all be measuring a common underlying property.

${ }^{2}$ Since the combined Computer Literacy/MIS is the simple average of those two components, it will automatically have a very high correlation with them individually. 
Table 3. Cross Correlations for Assessment Instrument Components

\begin{tabular}{|c|c|c|c|c|c|c|c|c|c|c|c|c|c|c|c|c|}
\hline \multirow{3}{*}{\begin{tabular}{|l|} 
Item \\
SA\&D \\
\end{tabular}} & \multirow{3}{*}{\begin{tabular}{c|} 
Mean \\
60.7 \\
\end{tabular}} & \multirow{3}{*}{$\begin{array}{c}\text { Std Dev } \\
15.6\end{array}$} & \multicolumn{14}{|c|}{ Pierson Correlations } \\
\hline & & & \multicolumn{2}{|c|}{ SA\&D } & \multicolumn{2}{|c|}{ Database } & \multicolumn{2}{|c|}{ Program } & \multicolumn{2}{|c|}{ CompLit } & \multicolumn{2}{|c|}{ MIS } & \multicolumn{2}{|c|}{ Telcom } & \multicolumn{2}{|c|}{ CL+MIS } \\
\hline & & & 1.000 & & 0.524 & $* * *$ & 0.367 & $* * *$ & 0.604 & $* * *$ & 0.594 & $* * *$ & 0.526 & $* * *$ & 0.645 & $* * *$ \\
\hline Database & 52.3 & 16.1 & 0.524 & **** & 1.000 & & 0.365 & $* * *$ & 0.596 & $* * *$ & 0.529 & $* * *$ & 0.339 & $* * *$ & 0.602 & $* * *$ \\
\hline Program & 50.2 & 17.2 & 0.367 & **** & 0.365 & $* * *$ & 1.000 & & 0.437 & $* * *$ & 0.403 & $* * *$ & 0.355 & $* * *$ & 0.451 & $* * *$ \\
\hline CompLit & 77.0 & 16.0 & 0.604 & **** & 0.596 & *** & 0.437 & *** & 1.000 & & 0.715 & $* * *$ & 0.501 & *** & 0.907 & $* * *$ \\
\hline MIS & 64.3 & 16.2 & 0.594 & **** & 0.529 & $* * *$ & 0.403 & $* * *$ & 0.715 & $* * *$ & 1.000 & & 0.452 & $* * *$ & 0.943 & $* * *$ \\
\hline Telcom & 53.7 & 15.4 & 0.526 & $* * *$ & 0.339 & $* * *$ & 0.355 & $* * *$ & 0.501 & $* * *$ & 0.452 & $* * *$ & 1.000 & & 0.511 & $* * *$ \\
\hline CL+MIS & 69.9 & 14.9 & 0.645 & $* * *$ & 0.602 & $* * *$ & 0.451 & $* * *$ & 0.907 & $* * *$ & 0.943 & $* * *$ & 0.511 & $* * *$ & 1.000 & \\
\hline \multicolumn{17}{|c|}{ *** Correlation is significant at the 0.001 level (2-tailed) } \\
\hline \multicolumn{17}{|c|}{ ** Correlation is significant at the 0.010 level (2-tailed) } \\
\hline
\end{tabular}

\begin{tabular}{|lc|}
\hline \multicolumn{2}{|c|}{$\begin{array}{c}\text { Table 4. Factor Analysis of } \\
\text { Assessment Instrument } \\
\text { Components } \\
\text { Com }\end{array}$} \\
Item & Factor \\
CompLit & 0.862 \\
MIS & 0.827 \\
SA\&D & 0.804 \\
Database & 0.740 \\
Telcom & 0.687 \\
Progrm & 0.614 \\
\hline
\end{tabular}

\section{Hypothesis Test}

The null hypothesis was tested using correlation analysis. The results are shown in Table 5. An additional Assessment Instrument component is shown here that was not included in Tables 3 and 4; the Overall component is the overall average of the other six basic components. In a perfect world, each subjective question would correlate only with the corresponding component on the Assessment Instrument. However, given the large number of significant crosscorrelations within each instrument, it is not surprising that almost all the components and questions have multiple significant correlations. However, there is still a discernable pattern in this table.

Table 5. Correlations for Assessment Instrument Components vs. Subjective Questions

\begin{tabular}{|c|c|c|c|c|c|c|c|c|c|c|c|c|}
\hline \multirow{2}{*}{\begin{tabular}{|l} 
Item \\
Overall \\
\end{tabular}} & \multicolumn{2}{|c|}{ Q01 } & Q02 & \multicolumn{2}{|c|}{ Q03 } & Q04 & \multicolumn{2}{|c|}{ Q05 } & \multicolumn{2}{|c|}{ Q06 } & \multicolumn{2}{|c|}{ Q07 } \\
\hline & 0.177 & $*$ & 0.055 & 0.241 & $* *$ & 0.057 & 0.194 & $*$ & 0.249 & $* * *$ & 0.150 & $*$ \\
\hline SA\&D & 0.147 & & 0.046 & 0.240 & $* *$ & 0.083 & 0.092 & & 0.195 & $* *$ & 0.197 & $* *$ \\
\hline Database & 0.116 & & -0.029 & 0.095 & & -0.009 & 0.077 & & 0.313 & $* * *$ & -0.096 & \\
\hline Progrm & 0.084 & & -0.065 & 0.159 & $*$ & 0.009 & 0.276 & $* * *$ & 0.155 & $*$ & 0.046 & \\
\hline CompLit & 0.143 & & 0.105 & 0.124 & & -0.014 & 0.126 & & 0.237 & $* *$ & 0.020 & \\
\hline MIS & 0.213 & $* *$ & 0.144 & 0.242 & $* *$ & 0.059 & 0.205 & $* *$ & 0.205 & $* *$ & 0.152 & $*$ \\
\hline Telcom & 0.100 & & 0.056 & 0.215 & $* *$ & 0.119 & 0.055 & & 0.053 & & 0.330 & $* * *$ \\
\hline $\mathrm{CL}+\mathrm{MIS}$ & 0.197 & $* *$ & 0.137 & 0.205 & $* *$ & 0.029 & 0.184 & $*$ & 0.236 & $* *$ & 0.101 & \\
\hline $\begin{array}{ll}* * * & \text { Correl } \\
* * & \text { Correl } \\
* & \text { Correl }\end{array}$ & $\begin{array}{l}\text { e } 0.001 \\
\text { e } 0.010 \\
\text { e } 0.050\end{array}$ & $\begin{array}{l}\text { leve } \\
\text { leve } \\
\text { leve }\end{array}$ & $\begin{array}{l}\text { (2-taile } \\
\text { (2-taile } \\
\text { l } 2 \text {-taile }\end{array}$ & & & & & & & & & \\
\hline
\end{tabular}

First we will examine the four components of the Assessment Exam which have a direct correspondence to one of the Learning Goals described in the subjective questions. The $\boldsymbol{S A} \boldsymbol{\&} \boldsymbol{D}$ component corresponds to Item Q03 (Systems Analysis \& Design). While this component has significant correlations with both Items Q06 (Database) and Q07 (Telecommunications), its strongest correlation is indeed with Item Q03. The Database component corresponds to Item Q06 (Database), and is significantly correlated with it and no other item. The Progrm component corresponds to Item Q05 (Programming). While this component has significant correlations with both Items Q03 (Systems Analysis \& Design) and Q06 (Database), its strongest correlation is indeed with Item Q03. The Telcom component corresponds to Item Q07 (Telecommunications). While this component has a significant correlation with Item Q03 (Systems Analysis \& Design), its strongest correlation is indeed with Item Q03. 
In the Annual Assessment Report, the composite component $\boldsymbol{C L}+\boldsymbol{M I S}$ is used to assess the goals associated with Items Q01 (MIS), Q02 (MIS Environment), and Q04 (Computer Architecture). As Table 5 shows, it is significantly correlated with only one of them, Item Q01. However, it is also correlated with three other items: Item Q03, Item Q05, and Item Q06, and two of those correlations are stronger than the correlation with Item Q01. It should be further noted that Items Q02 and Q04 have no significant correlations with any of the Assessment Instrument components.

\section{Summary and Conclusions}

This study has analyzed and compared two instruments used for assessing an undergraduate program in Information Systems. The objective Assessment Test has demonstrated significant correlations among all six of its components. Two reasons will be suggested for this phenomenon. One reason is that the discipline itself is very interdisciplinary, and although we break the curriculum out into seemingly independent courses, in reality the concepts are highly interdependent. For example, it is difficult for a student to become proficient at programming without an understanding of basic MIS, systems architecture, and systems analysis and design concepts. Certain concepts like basic hardware and operating systems architecture are threaded through all the courses in a typical curriculum. A second reason is a phenomenon that most of us in higher education are well familiar with. Students who are good at demonstrating recall through multiple choice tests in one course typically demonstrate that prowess in most courses.

The subjective questions also showed a high degree of cross-correlation among those seven items. Although the factor analysis indicates two somewhat distinct underlying factors, it would appear that at least five of the seven items are measuring some common characteristic. It is suggested here that that characteristic is some sort of satisfaction measure concerning the quality of education the students received.

Based on the analysis shown in Table 5, it is argued here that the null hypothesis can be partly, but not totally rejected. There is good evidence that four of the six objective assessment components are indeed measuring their respective learning objectives:

- Information systems development methodologies, techniques, and technologies. (Systems Analysis \& Design).

- $\quad$ At least one procedural programming language. (Programming).

- $\quad$ Database systems including data structure design and database design. (Database).

- $\quad$ Telecommunications systems including fundamentals of data communications, local area networks, and wide area networks. (Telecommunications).

However, it is also argued that the remaining three learning objectives are not being adequately measured:

- Information systems theory and concepts, and their application to the functional areas of business. (MIS).

- Information systems ethics, the impact of information systems on society, organizations, and individuals in both the domestic and international arena. (MIS Environment).

- $\quad$ Digital computer hardware, systems software, application software, peripheral equipment, and systems configurations. (Computer Architecture).

It is very clear that this part of the Assessment Test needs to be revised and appropriate components developed.

There is another important issue that underlies the assessment process that these results help to address. This is a very common issue encountered in most assessment programs in higher education. In our system it is very difficult to compel the student to participate in the Assessment Test and even more difficult to motivate the student to try to perform well on it. There is a statement in our college catalog that indicates that students may be required to participate in assessment activities. In our case, students are told that they are required to take the test in order to graduate, although we have never kept a student from graduating for not taking the test. And of course there is no minimum score used as an exit requirement. So there is nothing to really compel the student to participate or do anything more than randomly guess or straight line the answers. The average scores and the correlations found in this study would indicate that for the most part students are not randomly guessing nor straight-lining their answers. 
The methodology used here to attempt to validate the test was relatively simple and easy to implement. An alternative (or additional) approach that should be considered would be to compare the students' scores on the components with the grades received in the corresponding courses. Although the student records are available and accessible, it would be a time consuming exercise to look them up and manually enter them in the data table. But it is under consideration for a future project.

\section{References}

1. Anderson, D. R., Sweeney, D. J., and Williams, T. A. (1994). Statistics for Business and Economics, 5thed. Minneapolis/St. Paul: West Publishing Co.

2. $\quad$ Norusis, M. H. (1993). SPSS for Windows Base System User's Guide Release 6.0. Chicago: SPSS, Inc.

3. Tabachnick, B. G. \& Fidell, L. S. (1983). Using Multivariate Statistics. New York: Harper \& Row.

\section{Appendix: Subjective Instrument For The Knowledge Goals}

\section{CIS Degree Program Learning Objectives:}

\section{How well did we prepare you to meet the following Knowledge Goals?}

1. Information systems theory and concepts, and their application to the functional areas of business.
a) Worse than expected
b) About as expected
c) Better than expected

2. Information systems ethics, the impact of information systems on society, organizations, and individuals in both the domestic and international arena.
a) Worse than expected
b) About as expected
c) Better than expected

3. Information systems development methodologies, techniques, and technologies.
a) Worse than expected
b) About as expected
c) Better than expected

4. Digital computer hardware, systems software, application software, peripheral equipment, and systems configurations.
a) Worse than expected
b) About as expected
c) Better than expected

5. At least one procedural programming language.
a) Worse than expected
b) About as expected
c) Better than expected 
6. Database systems including data structure design and database design.
a) Worse than expected
b) About as expected
c) Better than expected

7. Telecommunications systems including fundamentals of data communications, local area networks, and wide area networks.
a) Worse than expected
b) About as expected
c) Better than expected

Notes 
Notes 